\title{
Preliminary Observations on Chemical Preference, Antipredator Responses, and Prey-Handling Behavior of Juvenile Leioheterodon madagascariensis (Colubridae)
}

\author{
AKIRA MORI* AND KOJI TANAKA \\ Department of Zoology, Graduate School of Science, Kyoto University, Sakyo, Kyoto, 606- \\ 8502 JAPAN
}

\begin{abstract}
Innate responses to prey chemicals, antipredator responses, and prey-handling behavior of a Madagascan colubrid snake, Leioheterodon madagascariensis, were experimentally examined. In a chemical test, ingestively naive hatchlings flicked their tongues frequently to the chemicals prepared from the animal taxa included in their natural diets, suggesting the presence of innate chemical prey preference. In a second test, three different types of stimuli were presented to elicit antipredator responses of the hatchlings. In a nonmoving stimulus session, only a single snake struck and exhibited characteristic displays such as body flattening, neck flattening, head elevation, and jerk. In a moving stimulus session, either no specific responses or a simple flight response was exhibited. In a tactile stimulus session, the above characteristic displays were frequently exhibited. Among these, lateral neck tilting posture accompanying head elevation and neck flattening was unique to $L$. madagascariensis. In a third test, five types of prey animals were offered to juveniles to examine the effects of prey size and type on prey-handling behavior, but no such effects were detected. Direction of ingestion seemed to depend on initial bite position. Constricting behavior was observed only in a single trial. All but one prey were swallowed alive. This inflexibility of prey-handling methods in the juvenile snakes may reflect the characteristics of generalist feeders, which require ontogenetic experiences to handle prey efficiently. Although $\boldsymbol{L}$. madagascariensis is considered to have well-developed Duvernoy's glands with enlarged, posterior maxillary teeth, the gland secretion did not seem to cause rapid death of prey.
\end{abstract}

Key words: Madagascar; Leioheterodon madagascariensis; Chemical preference; Antipredator behavior; Prey-handling behavior

\section{INTRODUCTION}

Madagascar is a biologically unique island

${ }^{*}$ Corresponding author. Tel: +81-75-753-4075; Fax: +81-75-753-4113

E-mail address: gappa@zoo.zool.kyoto-u.ac.jp (A. Mori) characterized by an abundance of endemic taxa. Currently, 17 genera of colubrid snakes are known from Madagascar, all of which are endemic to this island and adjacent islets 
(Randriamahazo, 1999). Because of this peculiarity, most previous studies on these snakes have focused on their taxonomy and biogeography, and little is yet known of behavioral and ecological aspects of the Madagascan snakes.

Leioheterodon madagascariensis is a relatively large (SVL $>100 \mathrm{~cm}$ ), common colubrid distributed throughout Madagascar (Glaw and Vences, 1994). Available information suggests that this species is a generalist predator feeding on a variety of vertebrates (Conant, 1938; Campbell and Murphy, 1977; Groves and Groves, 1978; Preston-Mafham, 1991; von Dathe and Dedekind, 1996; Mori and Randriamahazo, in press). It is also reported that $L$. madagascariensis is quite aggressive (Brygoo, 1982; von Dathe and Dedekind, 1996) and is potentially capable of envenomation through enlarged, posterior, maxillary teeth equipped with distinct Duvernoy's glands (Domergue and Richaud, 1971; Domergue, 1989; Mori, 2000). However, no systematic behavioral observations have been conducted for this species.

We experimentally examined three behavioral features of the juvenile L. madagascariensis: innate responses to prey chemicals, antipredator responses, and prey-handling behavior. These behavioral features have been well studied in many other colubrid species, but no comparable studies have been made for Malagasy snakes. Innate chemical preference to various animal taxa was examined using ingestively naive hatchlings. Characteristics of antipredator responses and prey-handling behavior are described, and the effects of stimulus and prey types on these behaviors were investigated. Basic information on reproductive traits is also provided.

\section{ANIMALS AND GENERAL METHODS}

A female L. madagascariensis (SVL=1293 $\mathrm{mm}$, body mass $=975 \mathrm{~g}$ ), collected in the dry forest at the Jardin Botanique A of Ampijoroa, northwestern Madagascar on 21 October 1999, laid ten eggs in a snake bag on 1 November. The eggs were removed from the bag and mea-
TABLE 1. Measurements of eggs of Leioheterodon madagascariensis. The shells of the lower five eggs were soft and yellowish. These eggs were preserved in formalin within five days after oviposition. Maternal body mass after oviposition was $685 \mathrm{~g}$.

\begin{tabular}{cc}
\hline Length $\times$ width $(\mathrm{mm})$ & Mass $(\mathrm{g})$ \\
\hline $54.2 \times 29.4$ & 26.5 \\
$54.2 \times 29.5$ & 26.9 \\
$59.7 \times 27.9$ & 26.1 \\
$53.2 \times 30.0$ & 25.7 \\
$53.9 \times 28.7$ & 25.0 \\
$48.8 \times 27.6$ & 22.0 \\
$49.8 \times 26.5$ & 21.4 \\
$51.0 \times 29.7$ & 20.6 \\
$45.1 \times 33.3$ & 17.5 \\
$45.0 \times 29.2$ & 17.6 \\
\hline
\end{tabular}

sured immediately (Table 1). Except for three soft yellowish eggs, which were apparently abnormal and thus were preserved in formalin immediately, the eggs were kept in a plastic box filled with wet sand at natural temperatures in Ampijoroa. On 4 November two more eggs turned yellowish and started to smell, and were preserved in formalin. The remaining five eggs were transported to our laboratory in Japan on 13 November, where they were kept in an environmental chamber at approximately $30^{\circ} \mathrm{C}$.

The eggs hatched from 26 to 29 January 2000. The hatchlings were measured (Table 2 ) and individually housed in a plastic cage $(295 \times 185 \times 165 \mathrm{~mm})$ provided with a paper floor covering, shelter, and water dish at room temperature between 25 and $30^{\circ} \mathrm{C}$.

TABLE 2. Measurements of hatchlings of Leioheterodon madagascariensis. SVL: snout-vent length, TL: tail length, BM: body mass.

\begin{tabular}{cccc}
\hline SVL $(\mathrm{mm})$ & TL $(\mathrm{mm})$ & BM $(\mathrm{g})$ & Sex \\
\hline 327 & 70 & 19.9 & $\mathrm{~m}$ \\
334 & 70 & 19.2 & $\mathrm{~m}$ \\
332 & 68 & 18.7 & $\mathrm{~m}$ \\
325 & 69 & 19.7 & $\mathrm{f}$ \\
320 & 64 & 18.9 & $\mathrm{f}$ \\
\hline
\end{tabular}


Chemical and antipredator response tests were conducted on 18 and 20 February, respectively. No foods were offered before these experiments. From 22 February, small mice (Mus musculus, 1.5-5.6 g) were provided basically twice a week. The prey-handling test was conducted from 20 July 2000 . The snakes were fasted for a week before the prey-handling test. Because of the small sample size, no statistical tests were conducted.

\section{CHMicAl Test}

It has been reported that in many colubrids ingestively naive snakes respond to chemical cues from species-typical prey with increased tongue flicking, indicating the presence of innate chemical prey preference (see Ford and Burghardt, 1993 for review). The first test was conducted to investigate responses of newly hatched, ingestively naive $L$. madagascariensis to chemicals from various groups of potential prey and to examine the occurrence of innate chemical prey preference in this species.

\section{Methods}

Preparation and presentation of chemical stimuli followed a well-established procedure employed for testing chemical discrimination by the vomeronasal organ in Squamata (Burghardt, 1970; Cooper, 1998). Cotton swabs bearing the chemical stimuli were presented to the snakes. The animals used for chemical stimuli represented a variety of taxa. They included earthworms (Oposthopora), slugs (Stylommatophora), fish (Cyprinidae, Carassius auratus; Adrianichthyidae, Oryzias latipes), frogs (Rhacophoridae, Rhacophorus $v$. viridis; Ranidae, Rana narina), newts (Salamandridae, Cynops ensicauda), lizards (Opluridae, Oplurus c. cuvieri; Scincidae, Eumeces elegans), snakes (Colubridae, Elaphe quadrivirgata, Rhabdophis tigrinus), birds (Ploceidae, Lonchura striata), and mammals (Muridae, baby and adult Mus musculus). All of these animals except for O. c. cuvieri and M. musculus are not sympatric with $L$. madagascariensis. Although it is ideal to use sympatric species to examine the chemical responses (see Cooper et al., 2000), unavailability of appropriate animals obliged us to use allopatric species. Nonetheless, our aim was to examine the responses of the snake to a given major taxon, not to a specific animal, and we believe that the above treatment did not substantially affect the results at that level. Distilled water and cologne (Fresh Floral, Mandam Co. Ltd, diluted to ca. $33 \%$ ) were used as controls for the experimental procedure and for detectable but biologically irrelevant odors, respectively.

Before the experiment, the cages of the snakes were moved onto the testing table, and water bowls, shelters, and paper floor coverings were removed. After more than $10 \mathrm{~min}$, the tip of a cotton swab, which was either rolled over the external surface of the animals or dipped into the control fluids just before each test, was presented $1-2 \mathrm{~cm}$ in front of the snout of the snake. The number of tongue flicks directed to the swab was counted for $60 \mathrm{sec}$ after the first tongue flick was observed. If no tongue flicks were made $30 \mathrm{sec}$ after the presentation of the swab, the tip of the swab was gently touched to the snout of the snakes. If the snake did not flick its tongue for $60 \mathrm{sec}$, the trial was terminated. A new stimulus was used for each snake.

The order of the presentation of the stimuli was randomized and counterbalanced. To make the blind test, the second author presented swabs to each snake without being informed of the source of the chemicals on each swab.

\section{Results}

There was considerable individual variation in the responses to the chemicals: one snake flicked its tongue at least once for all chemical stimuli, whereas another snake flicked its tongue to only three stimuli (two frog species and Oplurus chemicals). However, the mean numbers of tongue flicks showed a variation among the stimuli (Fig. 1). Snakes flicked their tongues frequently to the chemicals of frogs and reptiles and moderately to those of birds and mammals. Only a few tongue flicks 


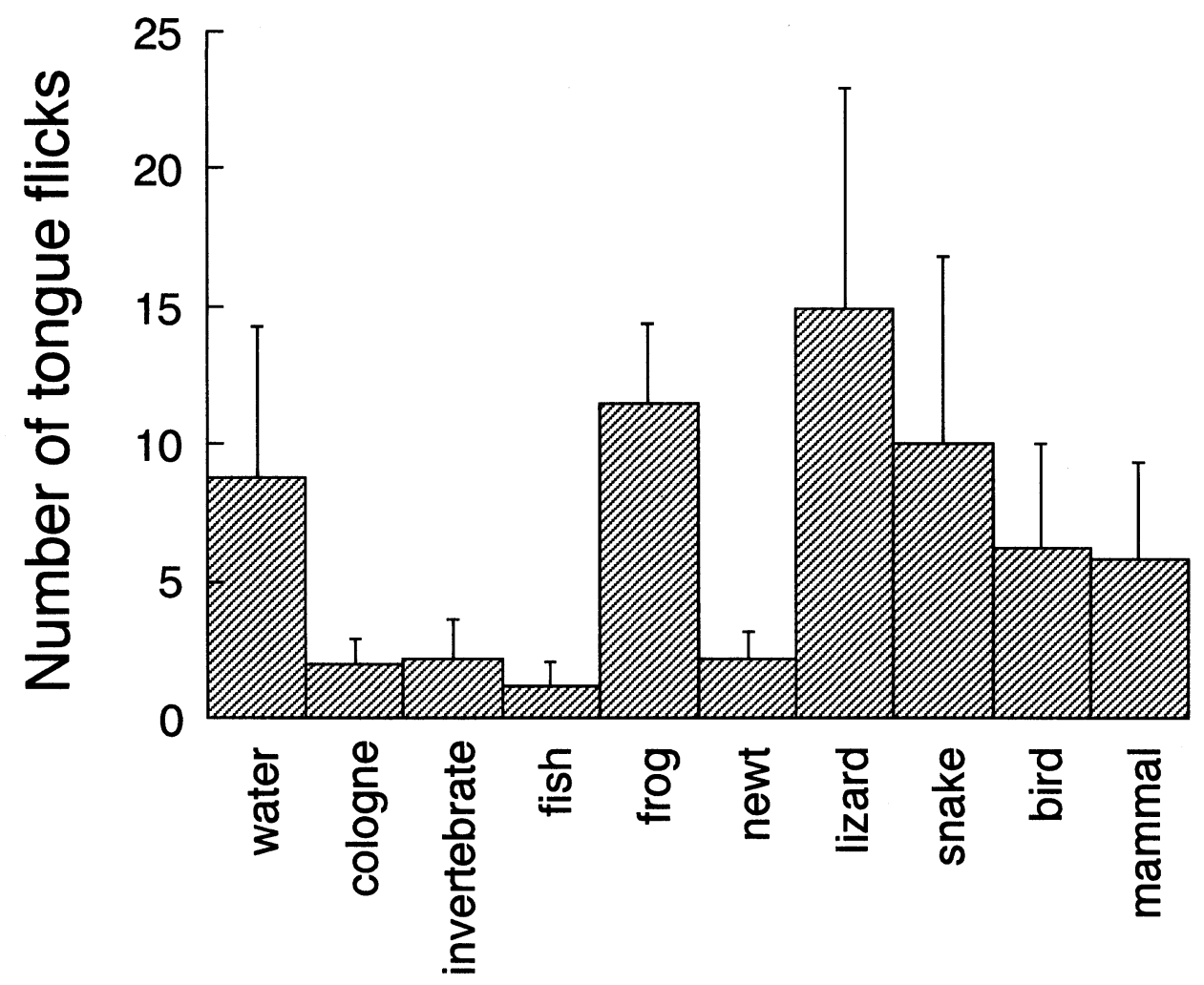

Chemical cues

FIG. 1. Mean number of tongue flicks made by hatchling Leioheterodon madagascariensis to cotton swabs bearing various chemical cues. Bars indicate 1SE.

were observed to the chemicals of cologne, invertebrates, fish, and newts. The mean of tongue flicks to the distilled water was moderately high (8.8), but this was apparently due to a high response of one individual: if this individual was excluded from the calculation, the mean tongue flick to the distilled water dropped to 3.5. No snakes attacked the stimuli.

\section{Discussion}

Available information on natural diets of $L$. madagascariensis suggests that this species is a generalist feeder, eating frogs, lizards, birds, and mammals (Preston-Mafham, 1991; Mori and Randriamahazo, in press). Chemicals from these animals elicited moderate to high tongue flick responses. It is suggested, therefore, that naive hatchlings can recognize, by chemical means, the food items utilized by this species in nature. In several species of snakes, newborns are known to respond to prey chemicals not only with increased tongue flicking but also by open-mouthed attack on the swab (Ford and Burghardt, 1993). The absence of attack in $L$. madagascariensis suggests that other stimuli, such as visual ones, may be indispensable to elicit prey attack in this species (Ford and Burghardt, 1993).

\section{ANTIPREDATOR RESPONSE TEST}

The aim of this experiment was to examine antipredator responses of neonate L. madagascariensis to various threatening stimuli and characterize the antipredator behaviors of this species. 


\section{Methods}

To elicit antipredator responses of the snakes, we used standardized methods developed for assessing levels of antipredator reactions of snakes (for non-tactile stimulus, Herzog and Burghardt [1986] and Herzog et al. [1989]; for tactile stimulus, Mori et al. [1996] and Mori and Burghardt [2000]). A snake was gently removed from its home cage and introduced into an arena $(44 \times 29 \times 30 \mathrm{~cm})$ at an ambient temperature of $24-25^{\circ} \mathrm{C}$. After leaving the snake undisturbed for five minutes, the experimenter slowly brought a forefinger to within 1 to $2 \mathrm{~cm}$ of the snake's snout and held it stationary for $60 \mathrm{sec}$. This is referred to as a nonmoving stimulus session. If the snake crawled away during the test, the experimenter followed it, keeping the extended finger in front of the snake. Then the snake was left undisturbed for $60 \mathrm{sec}$. The moving stimulus session began when the experimenter again extended the forefinger to within 1 to $2 \mathrm{~cm}$ of the snake's snout. This time he moved the finger back and forth at the rate of approximately three to four oscillations per second throughout the $60 \mathrm{sec}$ period. As with the nonmoving stimulus session, the experimenter kept the finger in front of the snake. The snake was then given another $60 \mathrm{sec}$ undisturbed period. Following this period, the tactile stimulus session, which lasted $60 \mathrm{sec}$, began. During this session the snake's body (excluding head and tail) was gently pinned every three sec for a total of 20 times, with a long metal snake hook. On the tip of the hook, a $50 \times 15 \mathrm{~mm}$ polyproplylene plate was attached so that the snake was pinned down by the plate.

In the first two sessions, we recorded the occurrences of "strike", "bite", and "flight", which are the main behavioral variables previously used in comparable studies. When the "strike" occurred, its frequency was recorded as well. Other characteristic behaviors observed, such as "body flattening" and "neck flattening" were also recorded. In the tactile stimulus session, behavior of the snake in response to each stimulus was observed and recorded. All sessions were videotaped, and videotape analysis was done to record the above variables.

\section{Results}

Only a single snake struck the nonmoving stimulus (twice) and exhibited characteristic displays such as body flattening, neck flattening, head elevation, and jerk (see below). Other snakes in the nonmoving stimulus session either showed no specific responses or simply fled (two snakes each). Toward the moving stimulus, two snakes exhibited no specific responses, and the other three showed a simple flight response.

In response to the tactile stimulus, one snake simply fled in response to all 20 stimuli. The other four snakes exhibited dorsoventral

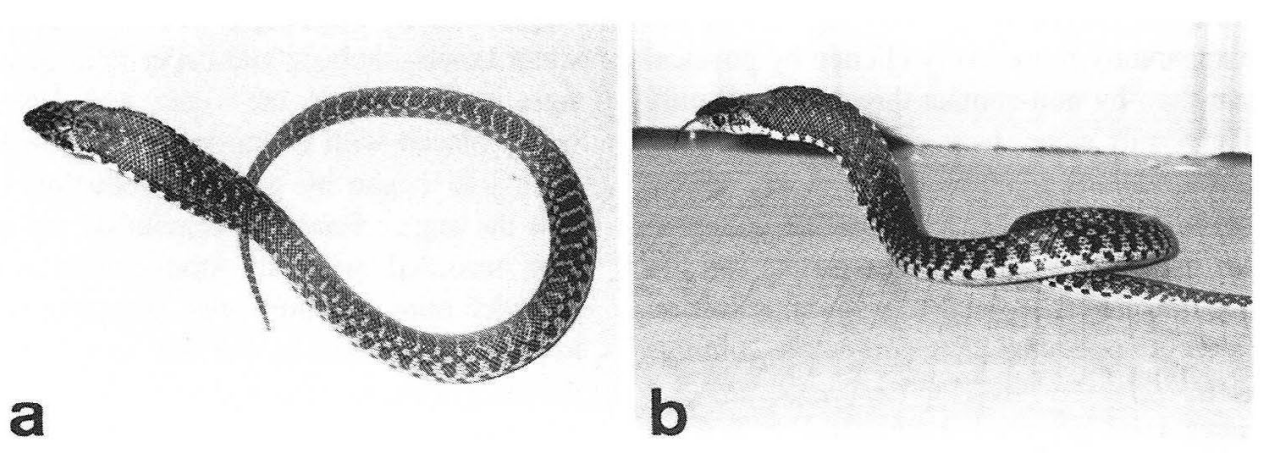

FIG. 2. Hatchling Leioheterodon madagascariensis exhibiting characteristic displays against artificial threatening stimuli. (a) Neck flattening accompanying slight head elevation and body flattening. (b) Neck flattening with prominent elevation and tilting of the anterior body so that the dorsal surface of the neck is directed toward the source of the stimulus. 
flattening of the neck (neck flattening) and/or flattening of the body posterior to the neck (body flattening; Fig. 2a), occasionally accompanied by lifting the head and neck region high above the substrate (head elevation). During head elevation, the snake often tilted the neck so that its dorsal surface was directed to the source of stimulus (Fig. 2b). From this posture, the snake frequently showed strikes with its mouth open in response to the stimulus (strike), but actual biting rarely occurred. In some cases, the snake irregularly formed circular or S-shaped loops with its neck and body flattened, and wriggled violently and intermittently in response to the physical contact of the stimulus (jerk). Average frequencies of these responses for the four snakes were 18.25 (neck flattening), 16.75 (body flattening), 9.0 (head elevation), 10.5 (strike), 3.75 (jerk), and 0.75 (flee).

\section{Discussion}

Body flattening and head elevation accompanying neck flattening are both common antipredator displays in snakes (Greene, 1988). Neck tilting during head elevation seems to be a characteristic display of $L$. madagascariensis. Antipredator responses similar to jerk of $L$. madagascariensis are known in other colubrids (e.g., Rhabdophis tigrinus, Mori et al., 1996) and members of other ophidian families such as the Elapidae (e.g., Maticora intestinalis, Mori and Hikida, 1991).

A suite of antipredator displays (neck flattening, head elevation, body flattening, and strike) were apparently more easily elicited by physical contact than by non-contact threatening stimuli. Similar results were observed in an Asian colubrid, Rhabdophis tigrinus (Mori et al., 1996). However, in the present test possible contribution of presentation order to the results can not be precluded because the tactile stimulus session was always conducted after non-tactile stimulus sessions.

\section{PREY-HANDLING TEST}

It has been demonstrated that as a consequence of behavioral adaptation, snakes change prey-handling behavior according to prey size and type: larger prey animals tend to be constricted to death, and then swallowed head first more frequently (Loop and Bailey, 1972; Mori, 1991); mammalian prey tends to be constricted to death prior to swallowing more frequently than ectothermic animals such as frogs (Gregory et al., 1980; Mori 1991); and certain prey animals are always swallowed head first regardless of their size (Voris et al., 1978; Mori 1998). The degree of such behavioral flexibility is, to some extent, species-specific (Halloy and Burghardt, 1990; Mori, 1996, 1997, 1998), and it has been suggested that dietary specialists change their behavior more efficiently than dietary generalists, especially when they are young (Drummond, 1983; Halloy and Burghardt, 1990; Mori, 1993, 1994, 1995, 1996).

The third test was conducted to examine the effects of prey size and type on prey-handling behavior of the juvenile L. madagascariensis that had been fed only one type of prey. Possible roles of Duvernoy's gland secretion in feeding were also examined.

\section{Methods}

Five types of prey animals were used: small mice (baby Mus musculus one to three days after birth, 1.7-2.0 g), large mice (juvenile M. musculus, 9.5-12.2 g), small frogs (metamorphosed Hyla japonica, 0.3-0.6 g), medium frogs (juvenile Rana nigromaculata, $1.8-2.3 \mathrm{~g}$ ), and large frogs (adult $R$. nigromaculata, 12.0-18.9 g). Approximately one hour prior to the experiment, water bowls, shelters, and paper floor coverings were removed from the cages, and the ceiling was replaced with a transparent acrylic board. Each trial began by gently introducing a prey into the cage. Feeding behavior of the snakes was recorded with an $8 \mathrm{~mm}$ video camerarecorder until the prey was completely swallowed. If the snakes did not attack the prey within $20 \mathrm{~min}$, the trial was terminated.

For the index of prey size, we used relative prey width (i.e., prey head width/snake head width), because width is generally considered a better indicator of the prey size than length or mass when evaluating the prey-handling 
efficiency of gape-limited predators (Pough and Groves, 1983; Mori, 1998). The following variables were recorded for each trial by analyzing the videotapes. Bite position: the site where the snake first seized the prey. Direction of prey ingestion: the prey was eventually swallowed "head first" or "hind legs (rump) first". Holding duration: time in sec from the initial seizure of the prey to the first "lateral jaw walking movements" by the snake in any direction. Manipulating duration: time in sec from the first lateral jaw walking movements to the commencement of swallowing. The commencement of swallowing was defined as the first jaw walking movements over the body of the prey in the direction in which the prey was subsequently swallowed. Swallowing duration: time in sec from the commencement of swallowing to the moment at which the prey was no longer visible externally. Condition of prey at swallowing: prey that made any movements, including breathing, during swallowing were considered "alive", otherwise "dead". Pattern of constricting or coiling behavior during prey-handling was also recorded, whenever observed.

\section{Results}

One individual did not attempt to eat small and large mice, and another did not eat a large mouse. All individuals readily struck and attempted to swallow the frogs regardless of their size. In all cases, snakes struck the prey immediately after the prey showed some kind of movement (locomotion, head turn, body adjustment, etc). Attempts were made to swallow two large frogs, but they were eventually regurgitated probably because the snakes were unable to engulf them completely due to their gape limitation (see below).

Irrespective of prey type, the direction of ingestion seemed to depend on the initial bite position: prey animals were swallowed head first when the bite position was located on the anterior part of the body including the head, and they were swallowed hind legs first when the bite position was located on the posterior part of the body including the hind legs (Table
TABLE 3. Relationships between the initial bite position and the direction of prey ingestion by juvenile Leioheterodon madagascariensis. Numerals indicate the numbers of prey animals.

\begin{tabular}{lcccc}
\hline & \multicolumn{4}{c}{ Bite position } \\
\cline { 2 - 5 } $\begin{array}{l}\text { Direction of } \\
\text { ingestion }\end{array}$ & Head & $\begin{array}{c}\text { Anterior } \\
\text { body }\end{array}$ & $\begin{array}{c}\text { Posterior } \\
\text { body }\end{array}$ & $\begin{array}{c}\text { Hind } \\
\text { leg }\end{array}$ \\
\hline Head first & 7 & 1 & 1 & 1 \\
Hind legs first & 0 & 0 & 7 & 5 \\
\hline
\end{tabular}

3). No apparent tendency for head first ingestion was recognized even for large mice and frogs. In trials with small and medium sized prey seven out of 14 were swallowed head first, and three out of eight large prey were swallowed head first. Except for one large frog, all prey animals were swallowed alive.

Constricting behavior was observed only in a single trial with a large mouse. Two seconds after a snake seized the rump of a mouse, inducing a vigorous struggling by the prey, the snake attempted to coil around the prey by typical wrapping and winding movements (Greenwald, 1978). However, the configuration of the coil was irregular and unstable, and the snake was not able to successfully coil around the prey. The prey continued to struggle, and the snake then tried to reconstrict the prey two more times, eventually holding three neat coils around the prey. However, the prey was not killed by constriction and was swallowed alive and rump first. Large mice and frogs in the other trials also struggled vigorously during the holding phase, but the snakes never attempted to constrict them.

Holding duration was quite short, and snakes began lateral jaw walking movements soon after the initial seizure (holding duration, $\bar{x}=2 \mathrm{sec}$, range $=0$ to 9 ). In all but one trial with small and medium sized frogs snakes began to swallow without manipulation phase. Manipulating duration was also short for small mice $(\bar{x}=8.3 \mathrm{sec}$, range $=2$ to 23$)$ and varied from 0 to $492 \mathrm{sec}$ for large frogs and mice $(\bar{x}=147 \mathrm{sec})$. Swallowing duration considerably increased when relative prey width exceeded 0.8 


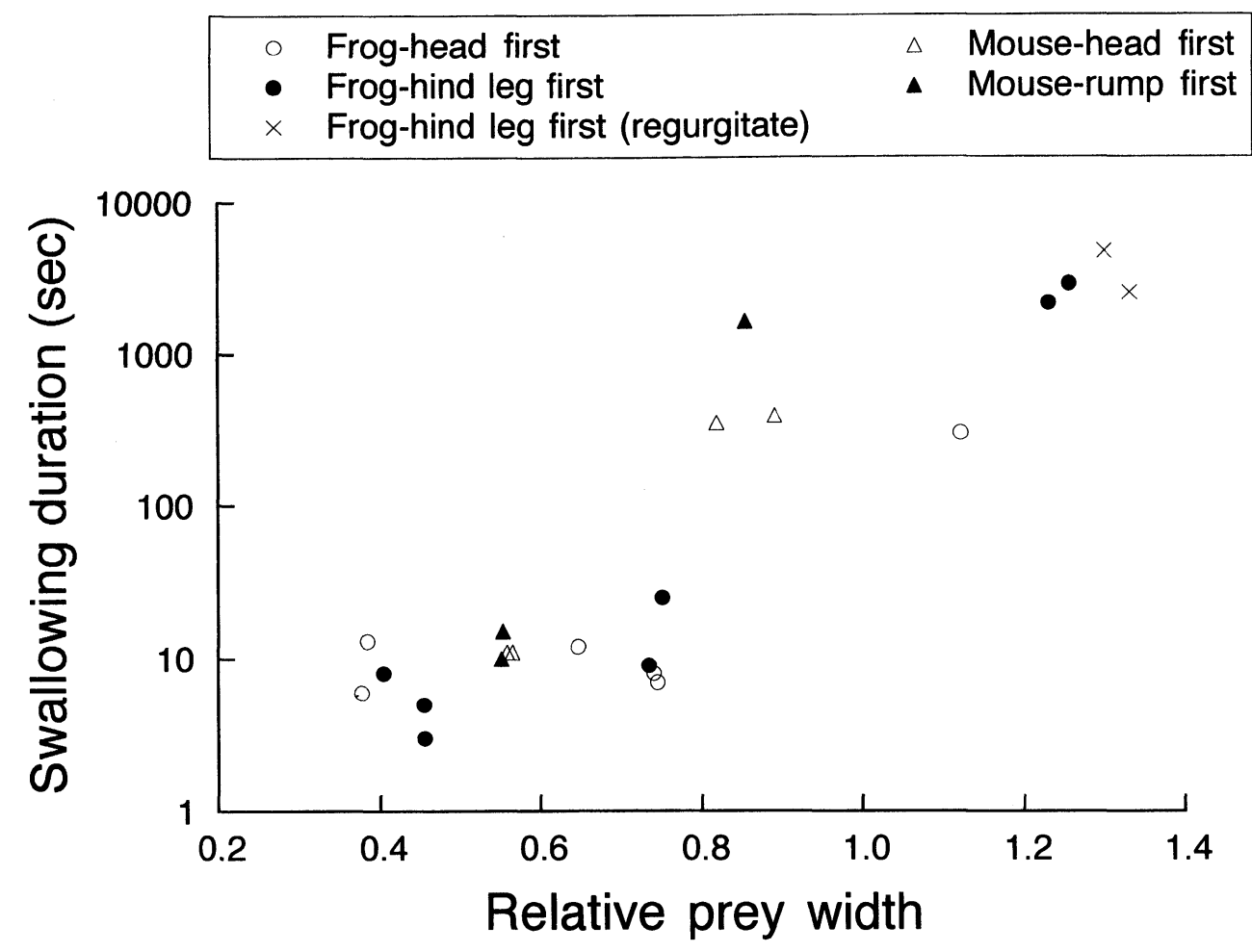

FIG. 3. Relationship between relative prey width (prey head width/snake head width) and swallowing duration in feeding trials of juvenile Leioheterodon madagascariensis. Direction of prey ingestion (head first or hind leg [or rump] first) is also shown.

(Fig. 3). For prey animals with relative prey width $<0.8$, direction of ingestion did not seem to affect the swallowing duration. For larger prey (relative prey width $>0.8$ ), however, head first ingestion was likely to enable the snakes to swallow prey quicker than hind leg first ingestion. In fact, two snakes that tried to swallow large frogs (relative prey width $=1.33$ and 1.30) hind leg first eventually abandoned the swallowing attempts after 42.4-min and 79.3-min, respectively: the snakes engulfed the frogs over their pectoral girdles but not their forelegs, and voluntarily regurgitated the frogs. In both cases the snakes initially began to swallow the frog from one of the hind legs letting the other stretch far anteriorly so that the tip of the latter leg reached anterior to the snout of the frog while swallowing. The snakes, left undisturbed for additional $10 \mathrm{~min}$ after regur- gitation, flicked their tongues toward the frogs frequently, but they never tried to swallow the regurgitated frogs (one dead and one alive) again. The live frog eventually died approximately 4 hours after regurgitation. Extensive bleeding during the swallowing phase was observed in three trials with large frogs.

\section{Discussion}

Virtually no effects of prey size and type on prey-handling behavior were detected in the juvenile L. madagascariensis. Adaptive function of head first ingestion of (large) prey has been considered to reduce swallowing duration by minimizing the resistance caused by the prey's appendages (Diefenbach and Emslie, 1971; Mori, 1991). Direction of prey ingestion in L. madagascariensis seems to basically depend on initial bite position. As a 
result, swallowing duration was prolonged when large prey was ingested hind leg first, and in the extreme cases, prey animals were eventually regurgitated after a prolonged swallowing attempt.

Selective advantage of constriction has been considered to prevent prey from retaliating or to reduce total feeding duration by killing or restraining the prey (Loop and Bailey, 1972; de Queiroz, 1984; Mori, 1991). In the present observations, except for a single large mouse, all prey were simply swallowed without any constricting attempt even though most of the large frogs and mice struggled vigorously during the handling phase. The single case of neat coiling indicates that $L$. madagascariensis is potentially capable of constriction from the viewpoint of morphological body plan, either to kill or simply restrain the prey. The ability of efficient constriction in L. madagascariensis may develop ontogenetically as in other generalist semi-constrictors such as Elaphe quadrivirgata (Mori, 1994, 1996).

The functional roles of Duvernoy's glands during feeding have been disputed and tested in several colubrid snakes (Kardong, 1982; Hayes et al., 1993; Rodríguez-Robles, 1994). After the initial seizure of prey, some snakes hold it with the jaws for a while presumably until the glands' secretion takes effect (Broadley, 1983; Jayne et al., 1988; Mori, 1998), and other snakes repeatedly open and close the jaws without shifting the position of bite (forceful chewing) probably to inject more secretion (Jansen and Foehring, 1983; Rodríguez-Robles, 1992; Thomas and Leal, 1993). In some cases, prey animals are killed during handling (Jayne et al., 1988; Mori, 1997), whereas in other cases they are only weakened and incapacitated (Mori, 1998). Some prey animals are swallowed alive without any sign of envenomation (Mori, 1997) or killed by constriction without any apparent assistance of the secretion (Rochelle and Kardong, 1993).

In L. madagascariensis initial holding duration was quite short, and no chewing-like behavior was observed. Although a single frog was recorded as "swallowed dead" on the basis of our definition, it is highly likely that the frog was still alive when the swallowing process was initiated because its body did not seem to lose tension throughout the process. Thus, virtually no prey would have been killed before the swallowing phase. However, the eventual death of the regurgitated frogs suggests that Duvernoy's secretion was delivered during prey-handling. These results suggest that Duvernoy's secretion of L. madagascariensis is insufficient to bring about rapid death of prey, but may be effective to incapacitate large prey when feeding duration is prolonged. Obviously L. madagascariensis offers an additional example of snakes with both well-developed Duvernoy's glands and potential for prey constriction during feeding (Shine, 1985; Rochelle and Kardong, 1993; Mori, 1998).

\section{CONCLUSION}

Our results showed that L. madagascarien$s i s$ is an ideal species for studies on various aspects of snake behavior. This snake is a dietary generalist, responds to chemical stimuli from various types of natural prey, has a rich repertoire of distinct antipredator displays, and possesses two representative prey subduing mechanisms of snakes (i.e., constriction and venom injection). Apparently inefficient prey-handling by the juvenile snakes suggests that this species is a good subject to study the ontogenetic development of prey-handling behavior as a representative of generalist feeders (see Mori, 1996). Further examination of these behavioral properties with greater sample size, coupled with comparisons involving snakes from other regions of the world, might shed light on the unique features of the behavioral evolution in Malagasy snakes, as well as on the ubiquitous behavioral patterns in snakes.

\section{ACKNOWLEDGMENTS}

We thank S. Yamagishi for giving us an opportunity to conduct this study and the 
staff of Parc Botanique et Zoologique de Tsimbazaza for their assistance with the field study. M. Toda, R. Yamamoto, J. Motokawa, H. Matsubara, and H. J. A. R. Randriamahazo helped us with obtaining prey animals. This study was partially supported by a Grant-in-Aid from the Monbusho under an International Scientific Research Program (Field Research, no. 11691183).

\section{LITERATURE CITED}

BROADLEY, D. G. 1983. FitzSimons' Snakes of Southern Africa. (Revised ed.), Delta Book, Cape Town. $376 \mathrm{p}$.

BRYGOO, E. R. 1982. Les ophidiens de Madagascar. Mem. Inst. Butantan 46: 19-58.

BuRghardT, G. M. 1970. Chemical perception in reptiles. p. 241-308. In: J. W. Johnston, JR., D. G. Moulton and A. Turk (eds.), Advances in Chemoreception, Vol. 1. Communication by Chemical Signals, Appleton-Century-Crofts, New York.

CAMPBELl, J. A. AND J. B. Murphy. 1977. Miscellaneous notes on the reproductive biology of reptiles. I. Two colubrid snake species from the Malagasy Republic, Leioheterodon madagascariensis and Madagascariophis colubrina (Reptilia, Serpentes, Colubridae). J. Herpetol. 11(2): 225-228.

ConANT, R. 1938. A note on eggs and young of Leioheterodon madagascariensis (Duméril \& Bibron). Zoologica 23: 389-393.

COOPER, W. E., JR. 1998. Evaluation of swab and related tests as a bioassay for assessing responses by Squamata reptiles to chemical stimuli. J. Chem. Ecol. 24(5): 841-866.

COOPER, W. E., JR., G. M. BURGHARDT, AND W. S. BROWN. 2000. Behavioural responses by hatchling racers (Coluber constrictor) from two geographically distinct populations to chemical stimuli from potential prey and predators. Amphibia-Reptilia 21(1): 103-115.

DE QUEIROZ, A. 1984. Effects of prey type on the prey-handling behavior of the bullsnake, Pituophis melanoleucus. J. Herpetol. 18(3): 333336.

DiefENBACH, C. O. AND S. G. EMSLIE. 1971. Cues influencing the direction of prey ingestion of the Japanese snake, Elaphe climacophora (Colubridae, Serpentes). Herpetologica 27(4): 461-466.

Domergue, C. A. 1989. Un serpent venimeux de Madagascar observation de deux cas de morsure par Madagascarophis (Colubridaé opisthoglyphe). Arch. Inst. Pasteur Madagascar, 56(1): 299-311.

Domergue, C. A. AND J. Richaud. 1971. Activité hémolytique des sécrétions des glandes de Duvernoy chez Lioheterodon (Colubridé aglyphe). Arch. Inst. Pasteur Madagascar, 40(1): 145-148.

DRUMMOND, H. 1983. Aquatic foraging in garter snakes: a comparison of specialists and generalists. Behaviour 86(1): 1-30.

Ford, N. AND G. M. BURGHARDT. 1993. Perceptional mechanisms and the behavioral ecology of snakes. p. 117-164. In: R. A. Seigel and J. T. Collins (eds.), Snakes. Ecology \& Behavior. McGraw-Hill, New York.

GLAW, F. AND M. VENCES. 1994. A Fieldguide to the Amphibians and Reptiles of Madagascar. (2nd ed.), Zoologisches Forschungsinstitut und Museum Alexander Koenig, Bonn. 480 p.

GREENE, H. W. 1988. Antipredator mechanisms in reptiles. p. 1-152. In: C. Gans and R. B. Huey (eds.), Biology of the Reptilia, Volume 16, Ecology B, Defense and Life History. Alan R. Liss, Inc, New York.

GREENWALD, O. E. 1978. Kinematics and time relations of prey capture by gopher snakes. Copeia 1978(2): 263-268.

Gregory, P. T., J. M. Macartney, and D. H. RIVARD. 1980. Small mammal predation and prey handling behavior by the garter snake Thamnophis elegans. Herpetologica 36(1): 87-93.

GROVES, F. AND J. D. GROVES. 1978. Fatal toad poisoning in snakes. Herpetol. Rev. 9(1): 19-20.

HAYES, W. K., P. LAVín-MURCIO, AND K. V. KaRDONG. 1993. Delivery of Duvernoy's secretion into prey by the brown tree snake, Boiga irregularis (Serpentes: Colubridae). Toxicon 31(7): 881887.

Halloy, M. AND G. M. BuRGHARDT. 1990. Ontogeny of fish capture and ingestion in four species of garter snakes (Thamnophis). Behaviour 112(3/4): 299-318.

HerzoG, H. A., JR. AND G. M. BURGHaRdT. 1986. Development of antipredator responses in snakes: I. Defensive and open-field behaviors in newborns and adults of three species of garter snakes (Thamnophis melanogaster, T. sirtalis, T. butleri). J. Comp. Psychol. 100(4): 372-379.

HerzoG, H. A., JR., B. B. Bowers, AND G. M. BURGHARDT. 1989. Stimulus control of antipredator behavior in newborn and juvenile ga ter snakes (Thamnophis). J. Comp. Psychol. 103(3): 233-242.

JANSEN, D. W. AND R. C. FoEHRING. 1983. The mechanism of venom secretion from Duvernoy's gland of the snake Thamnophis sirtalis. J. Morphol. 175(3): 271-277.

JAYNE, B. C., H. K. VoRIS, AND K. B. HEANG. 1988. Diet, feeding behavior, growth, and numbers of a 
population of Cerberus rynchops (Serpentes: Homalopsinae) in Malaysia. Fieldiana Zoology, New Ser. (50): 1-15.

KARDONG, K. V. 1982. The evolution of the venom apparatus in snakes from colubrids to viperids \& elapids. Mem. Inst. Butantan 16: 105-118.

LOOP, M. S. AND L. G. BAILEY. 1972. The effect of relative prey size on the ingestion behavior of rodent-eating snakes. Psychon. Sci. 28(3): 167-169.

MORI, A. 1991. Effects of prey size and type on prey-handling behavior in Elaphe quadrivirgata. J. Herpetol. 25(2): 160-166.

MORI, A. 1993. Prey handling behavior of neonatal rat snakes, Elaphe taeniura and E. dione (Colubridae). Jpn. J. Herpetol. 15(2): 59-63.

MORI, A. 1994. Prey handling behavior of newly hatched snakes in two species of the genus Elaphe with comparison to adult behavior. Ethology 97(3): 198-214.

MORI, A. 1995. Prey handling behavior of young rat snake, Elaphe taeniura (Squamata: Reptilia). Mem. Fac. Sci. Kyoto Univ. Ser. B. 16: 43-47.

MoRI, A. 1996. A comparative study of the development of prey handling behaviour in young rat snakes, Elaphe quadrivirgata and E. climacophora. Herpetologica 52(3): 313-322.

MORI, A. 1997. A comparison of predatory behavior of newly hatched Rhabdophis tigrinus (Serpentes: Colubridae) on frogs and fish. Jpn. J. Herpetol. 17(2): 39-45.

MORI, A. 1998. Prey-handling behavior of three species of homalopsine snakes: features associated with piscivory and Duvernoy's glands. J. Herpetol. 32(1): 40-50.

MORI, A. 2000. A case of envenomation by the Madagascan colubrid snake, Leioheterodon modestus. Snake 29(1/2):(in press)

MorI, A. AND G. M. BURGHARDT. 2000. Does prey matter? Geographic differences in antipredator responses in hatchlings of a Japanese colubrid snake, Rhabdophis tigrinus. J. Comp. Psychol. 114(4):408-413

MORI, A. AND T. HIKIDA. 1991. Notes on defensive behavior of the Asian elapid, Maticora intestinalis. Snake 23(2): 107-109.
Mori, A. AND H. J. A. R. RANDRIAMAhAzo. (in press) Leioheterodon madagascariensis (Madagascar Menarana Snake). Diet. Herpetol. Rev.

MORI, A., D. LAYNE, AND G. M. BURGHARDT. 1996. Description and preliminary analysis of antipredator behavior of a colubrid snake having nuchal glands, Rhabdophis tigrinus tigrinus. Jpn J. Herpetol. 16(3): 94-107.

Pough, F. H. AND J. D. GROVES. 1983. Specializations of the body form and food habits of snakes. Amer. Zool. 23(2): 443-454.

Preston-MafHAM, K. 1991. Madagascar, A Natural History. Facts On File, Oxford. 224 p.

RANDRIAMAHAZO, H. 1999. Reptiles in Madagascar. p. 167-212. In: Yamagishi, S. (ed.), The Animals of Madagascar: Its Wonderful Adaptive Radiation. Shokabo, Tokyo. (in Japanese)

Rochelle, M. J. AND K. V. Kardong. 1993. Constriction versus envenomation in prey capture by the brown tree snake, Boiga irregularis (Squamata: Colubridae). Herpetologica 49(3): 301-304.

Rodríguez-Robles, J. A. 1992. Notes on the feeding behavior of the Puerto Rican racer, Alsophis portoricensis (Serpentes: Colubridae). J. Herpetol. 26(1): 100-102.

Rodríguez-Robles, J. A. 1994. Are the Duvernoy's gland secretions of colubrid snakes venom? J. Herpetol. 28(3): 388-390.

SHINE, R. 1985. Prey constriction by venomous snakes: a review, and new data on Australian species. Copeia 1985(4): 1067-1071.

THOMAS, R. AND M. LEAL. 1993. Feeding envenomation by Arrhyton exiguum (Serpentes: Colubridae). J. Herpetol. 27(1): 107-109.

Voris, H. K., H. H. VORIS, AND L. B. LIAT. 1978. The food and feeding behavior of a marine snake, Enhydrina schistosa (Hydrophiidae). Copeia 1978(1): 134-146.

Von DAThe, F. AND K. DEDEKIND. 1996. Pflege und Vermehtung von Madagaskar-Hakennattern (Leioheterodon madagascariensis Duméril \& Bibron, 1854) im Tierpark Berlin-Friedrichsfelde. Zool. Garten N. F. (66): 69-76. 